\title{
浅谈合理选用识字方法，提高阳光识字效率
}

梁燕媚

佛山市顺德区陈村镇石洲小学

DOI:10.32629/jief.v2i6.1018

[摘 要] 识字方法的运用要根据教材内容的特点、学生的认知程度、教学手段的使用, 合理、科学、有效地选择相应的识字教学方法。每一 种识字方法都有其优缺点, 在使用时, 教师应自主权衡哪一种识字方法能最大限度地提高阳光识字课堂的效率, 就选择运用那一种的识字方 法。笔者具体分析了四种识字方法, 让读者清晰明了地掌握应用识字方法, 方便同行有效提高识字效率。

[关键词] 随文识字字; 族识字; 字源识字; 字理识字; 识字效率

中图分类号: G623.22 文献标识码: A

在小学阶段, 识字方法是多种多样的。选择哪一种识字方式, 能否 最大限度地提高识字效率, 主要看学生的年龄特点、心理特点、接受能 力、文本特性以及课堂状态。无论采用哪种识字方式, 都要以增强教学 力度, 提高识字效率为最终目的。

低段识字课堂的识字方式, 本人在教学实践中主要实践探讨随文识 字、字族识字、字源识字、字理识字。下面, 本人对每种识字方式进行 理念内涵、优缺点、具体操作模式、实践案例四个方面进行论述。

\section{1 随文识字的实践与探索}

1. 1 随文识字的内涵

部编教材一年级课文是阅读教材, 也是识字教材, 一年级的阅读教 学要以识字教学为中心。这种在文本中识字的方式称作 “随文识字法” 。

1.2 随文识字法的优劣

\subsection{1 随文创设了识字的语言环境}

随课文识字, 首先集中识字词, 然后在课文中重现, 这中文本环境 是其他语言环境不可替代的。通过课文的各种形式朗读, 生字词可以及 时得到复习。读课文是接受规范语言的熏陶, 是进一步理解字词, 对写 话中的错别字有效减少。

\subsection{2 随文便于理解字义}

解读文本的时候, 教师可以运用多种方法引导学生理解字词的意思。 低段理解字义时, 教师要形象化、动态化、生活化。随文解义为学生减 轻压力, 为教师的识字教学设计减轻负担。

\subsection{3 随文影响识字效率}

随文忽略汉字本身的构字规律和科学系统, 对字形的理解认知记忆 缺乏科学性。随文识字的实质是分散识字, 不是批量识字, 影响了识字 效率.

2 字族识字的实践与探索

\section{1 字族识字的内涵}

同从一个声符的汉字, 有的只起表音作用, 有的不仅表音, 还兼顾 表义的作用。表音兼表义的归纳在一起, 叫做 “字族” 。在识字教学中, 相机运用字族的识字方式, 对提高学生的识字效率具有一定的帮助。字 族识字是先选字后编文, 以字归族, 以族为文, 文统字族。

\section{2 字族识字的优劣}

2. 2.1 字族文利于识记汉字的音、形、义

汉字的音、形、义三者之间辩证而统一的关系, 在字族文识字教学 中得到充分的体现。这种字形类联、字音类聚、字义类推的识字方式方 法, 简化了汉字的识记时间, 便于鉴别, 利于拓展, 节省了教学时间, 使学生在短时间里掌握了大量的汉字字形, 大大提高了识字的效率。

\subsection{2 字族文识字利于提前阅读和写话}

字族识字法可以帮助学生增加识字量, 提高识字效率。识字量的增 加, 极大地拓宽了学生阅读的兴趣, 提前了写话的起步。

$$
\begin{aligned}
& 2.3 \text { 字族识字的教学应用 } \\
& \text { 字族 识 字 } \\
& \text {-- }
\end{aligned}
$$

【一】教学目标

认识字族 、字族文;

认识 “饱、泡、跑、抱、袍、炮” 六个生字。

【二】教学互动过程

1. 介绍字族和字族文

师: “河水清清天气晴, 小小青蛙大眼睛……”这篇课文里有哪几 个字很像?

生:清、晴、睛、请

师：还有跟它们相像的字吗? 
师: 这几个字都很像, 我们怎样才能记住它们呢?

师: 通过这篇有趣的课文, 我们很容易地把这几个字记清楚了。

\section{3 字理识字的实践与探索}

3.1 字源识字的特性

3.1.1 字源识字是一种遵循汉字属性与儿童认知规律的方法。

汉字属于表义性的文字, 形象直观、逻辑严密、系统性强。教学实 践证明: 深入浅出地剖析汉字的构字理据, 有助于儿童的理解和记忆, 能 有效地提高识字效率。例如：在教学象形字 “日” 时, 我将 “日” 字的 演变过程一一展示, 这样, 学生就能在头脑中建立起文字符号与实际事 物之间的相似联系, 形成栩栩如生的表象。

\section{1 .2 字源识字注重文化的传承}

字源识字法, 既强调帮助学生从汉字本源出发理解汉字的构造和意 义, 合理、准确、快捷地解决汉字问题, 也注重充分发掘汉字文化的丰 富营养字法, 一方面提高汉字教学的直观性和趣味性, 实现有意义的汉 字教学, 提高识字质量和识字效率; 另一方面深挖汉字的文化基因, 帮 助学生积累文化知识、发展思维能力, 培养学生热爱祖国语文的思想感 情。例如: “学” 的下半部分表示一个小孩站在门口观察外面世界的变 化, 上半部分表示知识和感悟不断地积累起来; “习” 是一只小鸟在不 断地练习飞行, 指不断地练习。因此, “学习” 的本意是为适应外界和 未来的生活, 不断地练习, 积累生存的本领。它的引申义指学习是有深 度和层次之分的。

\section{1 .3 字源识字利用图案, 让学生观察由图到线到字的发展}

一年级识字课利用字源识字的方法, 就是将我们正在学习和使用的 汉字, 从图画式的甲骨文, 到线条化的金文、小管、汉隶、草书, 直到 现在的简化字, 引导孩子观察汉字由图画到线到字, 提高识字效率。心 理学研究发现: 儿童把汉字当成一个个完整的图形来记忆, 这种图形属
于形象识记能力的一种。幼儿期的学生认汉字的速度很快, 因为他们把 汉字当作一幅幅图画, 孩子就在记住图画的过程中, 认识了一个又一个 的汉字。例如: 部编教材一年级上册《日月水火》一课, 关于象形字的 拓展, 如下图示。

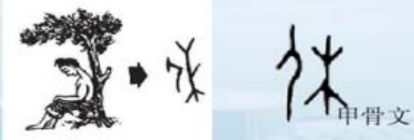

\section{2 字源识字的模式}

人生读书识字始。字源识字的具体形式: 创建系统的字源识字资料; 运用网络识字课堂; 开发校本字源识字读本; 编制相关的字源识字课堂 游戏; 字源讲解度适合学生的认知程度。这种识字法追根溯源, “音、 形、义” 结合, 有效吸引学生的注意力; “形、义” 相行, 促进识字的 有效迁移; 字根为本, 识字效果显著。

综上所述, 小学低段的语文教学, 识字是重点。在识字教学实践中, 教师应根据不同课型不同生字选择运用行之有效的识字方法(随文识字、 字族识字、字理识字、字源识字)，从而合理高效地提高识字教学的效率。

\section{[参考文献 $]$}

[1]王琳琳.借统编教材春风, 实施字源识字教学 [J]. 天津教 育,2020(18):116-117.

[2]郭艳飞. 从字源识字法探究小学低年级识字教学 [J]. 吉林教 育,2020(Z2):130

[3] 张英.关于字源的识字教学策略研究 [J]. 小学生作文辅导(上 旬),2019(12):57-58.

[4]李玲,韩庆艳.字源识字教学设计影响因素及对策研究[J].现代交 际,2019(21):69+68. 